\title{
Role of visual inspection of cervix with acetic acid and high risk human papilloma virus DNA testing in screening for cervical cancer
}

\author{
Neha Gami $^{1}$, Gauri Gandhi ${ }^{1}$, Swaraj Batra ${ }^{1}$, Vijay Zutshi ${ }^{1}$, B. C. Das ${ }^{2}$, Suresh Bhambhani ${ }^{2}$ \\ ${ }^{1}$ Department of Obstetrics \& Gynecology, Maulana Azad Medical College, Delhi, India \\ ${ }^{2}$ Institute of Cytology \& Preventive Oncology, Indian Council of Medical Research, Noida, India
}

Received: 4 February 2013

Accepted: 22 March 2013

\section{Correspondence:}

Dr. Neha Gami,

E-mail: nehagami@hotmail.com

(c) 2013 Gami N et al. This is an open-access article distributed under the terms of the Creative Commons Attribution License, which permits unrestricted use, distribution, and reproduction in any medium, provided the original work is properly cited.

\begin{abstract}
Background: To evaluate the role of VIA alone and in combination with high risk Human Papilloma virus DNA testing as a screening test for cervical dysplasia and cancer.

Methods: 400 symptomatic patients from the gynecology outpatient department were screened using Pap smear and VIA. HPV DNA testing was done for 62 VIA positive and 100 VIA negative women. Colposcopy was done for all women. Those found positive on any or all of the screening tests were subjected to cervical biopsy. The results were analysed for PAP, VIA, HPV and a combined test using VIA and HPV both.

Results: VIA had the highest sensitivity (91\%) to detect any grade of dysplasia. The sensitivity of the combination test (VIA + HPV) was $80.6 \%$ which was lower than that of VIA (91\%) and also lower than that of HR HPV DNA detection $(86 \%)$. The specificity of the combination test (VIA + HPV) was $68.3 \%$ which was significantly higher than that of VIA alone $(39 \%)(\mathrm{p}=0.000)$ and also higher than that for HPV DNA detection when used alone $(56 \%)$. Pap smear had the highest specificity $(95.12 \%)$ but sensitivity was much lower at $52.7 \%$.

Conclusions: VIA is a highly sensitive screening test. The main disadvantage is its low specificity. However the combination test of VIA + HR HPV testing overcomes this and at the same time maintains a high sensitivity. Thus a test which combines VIA plus HR HPV testing is better screening method than either of the three tests (VIA, HPV, PAP) done alone.
\end{abstract}

Keywords: VIA, Human Papilloma Virus, Screening, Cancer cervix

\section{INTRODUCTION}

The commonest malignancy found in Indian women is cervical cancer. In India about 100,000 women develop this cancer every year ${ }^{1}$ constituting about $16 \%$ of the world's annual incidence of cancer $^{2}$ In developed countries the incidence of cervical cancer has decreased due to screening, early detection and treatment. However, in developing countries, $80 \%$ of cervical cancers are incurable at the time of detection due to their advanced stage. ${ }^{3}$ Therefore, screening for pre invasive and early invasive lesions of the cervix is a priority in the developing world.
Pap smear has been the standard screening test used in India. But it has several limitations. This screening method has low sensitivity. Also, it requires trained cytopathologists and technicians. And in a developing country like India many of the patients are lost to follow up. Therefore a need was felt to investigate other screening modalities.

An alternate screening test is Visual Inspection of the cervix with Acetic acid (VIA), VIA is a highly sensitive screening test. It is especially suited for a country like ours because of its low cost and minimal technological requirements. However, the main disadvantage is its low specificity leading to high false positive screens. In order 
to improve its specificity attempts have been made to combine it with a secondary triage procedure like Human Papilloma Virus DNA testing.

Persistent High risk Human Papilloma virus infection is a known risk factor for cervical cancer. In most cases, cervical intraepithelial carcinoma is assumed to be preceded by a period of HPV infection. $80-99 \%$ of invasive cervical cancers ${ }^{3}$ and $63-72 \%$ of high grade dysplasia $^{4,5}$ are positive for high risk HPV DNA. However it must be kept in mind that $5-40 \%$ of all women in the reproductive age group are also positive for high risk HPV DNA. This means that all cases positive for HR HPV DNA are not necessarily harboring cervical cancer or any of its precursor lesions. Thus, the exact role of HPV DNA testing as a screening test is yet to be established.

This study was designed to evaluate whether the addition of High risk HPV DNA testing to a simple test like VIA could prove to be better and more effective screening strategy than either test alone or screening by Pap smear.

\section{METHODS}

This study was carried out in the Department of Obstetrics and Gynecology, Maulana Azad Medical College (MAMC) and associated, Lok Nayak Hospital New Delhi. Over a period of one year, 400 patients amongst those attending the gynecology OPD were included in the study.

Multiparous women in the reproductive age group presenting with history of any or all of the following were included:

(i) Discharge per vaginum

(ii) Inter-menstrual bleeding

(iii) Post coital bleeding

(iv) Clinically suspicious looking cervix
Nulliparous patients, pregnant patients, patients with active bleeding per vaginum and patients with frank growth on the cervix were excluded from the study.

An informed consent was taken from all subjects. After obtaining a detailed history, all the patients were subjected to a general, systemic and local examination.

All patients then underwent unaided visual examination using a cuscos speculum. A Pap smear was taken using an Ayre's spatula. The Pap smear was prepared by smearing the material obtained on the ayre's spatula on a glass slide and immediately fixing it in $95 \%$ alcohol. A smear for HPV DNA detection was taken for 58 VIA positive women and 104 controls (VIA negative). A larger number of controls were taken as there is a higher chance of finding HPV DNA in VIA positive cases. The smear for HPV DNA detection was prepared by smearing the material on a paper slide ${ }^{6}$ made of Whatman $3 \mathrm{~mm}$ sterile filter paper. This paper slide was stored in a polythene pouch. Acetic acid diluted to $5 \%$ was then applied to the cervix, using a swab stick, and visual inspection with acetic acid (VIA) was done after one minute. This was followed by colposcopy for all patients.

All Pap smears and cervical tissue specimens obtained on biopsy were processed and diagnosed in the cytopathology division of Institute of Preventive Oncology (ICPO), ICMR in MAMC New Delhi. All the slides were examined by the same cytopathologist, and reported according to Bethesda III, to maintain uniformity in reporting.

Polymerase chain reaction (PCR) for the detection of High Risk Human Papilloma Virus (Type 16 and 18) DNA was carried out in the molecular oncology division of ICPO, ICMR in MAMC, Delhi. The oligonucleotide sequences used are shown in Table 1.

Table 1: Oligonucleotide primer sequences used for the amplification of different HPV types and $\beta$-globin gene.

\begin{tabular}{|c|c|c|}
\hline Primer & $\begin{array}{l}\text { Amplifier Size } \\
\text { (bp) }\end{array}$ & Primer sequence \\
\hline \multicolumn{3}{|c|}{$\begin{array}{l}\text { Consensus Primer } \\
\text { MY } 11\end{array}$} \\
\hline MY 09 & 450 & 5'CGTCCMAARGGAWACTGATC3' \\
\hline HPV 16 & 217 & $\begin{array}{l}\text { 5'-AAG GCC AAC TAA ATG TCA C-3' } \\
\text { 5'-CTG CTT TTA TAC TAA CCG G-3' }\end{array}$ \\
\hline HPV 18 & 100 & $\begin{array}{l}\text { 5' ACCTTAATGAAAAACCACGA-3', } \\
\text { 5' CGTCGTTTAGAGTCGTTCCTG-3' }\end{array}$ \\
\hline$\beta$-globin & 268 & $\begin{array}{l}\text { 5'-GAA GAG CCA AGG ACA GGT AC-3', } \\
\text { 5'- CAA CTT CAT CCA CGT TAC ACC- } 3\end{array}$ \\
\hline
\end{tabular}

$\mathrm{M}-\mathrm{A}$ or $\mathrm{C}, \mathrm{R}-\mathrm{A}$ or $\mathrm{G}, \mathrm{W}-\mathrm{A}$ or $\mathrm{T}, \mathrm{Y}-\mathrm{C}$ or $\mathrm{T}$ 
The criteria for being considered test positive for the four tests was as follows: for the pap smear, a finding of LSIL or worse; for HPV , the presence of HPV 16 or 18 DNA by PCR; for VIA the presence of a distinct aceto-white area; for colposcopy reid index score ${ }^{7}$ of 3 and above.

Cervical Biopsy was taken if indicated i.e. in all cases having a reid index of 3 or more on colposcopy. The biopsy was obtained either by a cervical punch biopsy forceps or a loop biopsy was taken. The examination was concluded with a per vaginum examination to rule out other pelvic pathologies.

Biopsies revealing mild dysplasia or worse lesions on histopathology were considered as true positive cases. Biopsies showing chronic cervicitis, chronic cervicitis associated with koilocytic changes were considered negative.

All results were compiled and subjected to statistical analysis. The sensitivity, specificity, predictive value of positive test, predictive value of negative test, percentage of false positives and percentage of false negatives were calculated for the following tests with biopsy taken as the gold standard.

1. Pap smear

2. VIA

3. High risk HPV DNA detection

4. Colposcopy

5. The combination test "VIA positive + HPV positive"

6. Combination of "Pap positive + HPV positive"

7. Combination of "VIA positive + Pap positive"

\section{RESULTS}

The mean age of the subjects in the study group was 32.22 years. Amongst the women with CIN the mean age was 36.02 years $(p>0.05)$. The majority of women screened $(52.1 \%)$ were para 3 or 4 . The mean parity was 2.82. The mean parity among women with CIN was 3.11 $(p>0.05)$. Amongst the general population, the mean age at first coitus was 18.36 years with $71 \%$ of the cases having first coitus before 19 years. On the other hand, $80.5 \%$ of the women with CIN had first coitus before 19 years of age with the mean age being 17.43 years. Only $3.5 \%$ of the population were using oral contraceptive pills.

The most common presenting symptom in the majority of women $(89.2 \%$ ) was discharge per vaginum, followed by pain lower abdomen and backache (7.0\%). Other complaints included pruritus vulva, intermenstrual bleeding, post coital bleeding, dyspareunia and dysuria.

The most common finding on speculum examination was chronic cervicitis (41\%). This was followed by erosion (34\%) and normal cervix in $24 \%$.

Amongst the 400 women screened, Pap smear was reported as normal or inflammation in 379 (94.6\%) and abnormal in $21(5.4 \%)$. 21 abnormal smears included 7 LSIL, 9 LSIL with HPV infection, 3 HSIL and 2 with cells suspicious of malignancy. Thus out of 400 women screened Pap showed LSIL in $4.1 \%$, HSIL in $0.8 \%$ and suspicion of malignancy in $0.5 \%$. ASCUS was reported in $1 \%$ smears. 197 out of 400 smears (49.3\%) had inflammation. 50 out of 400 smears (12.5\%) showed inflammation with infection, of which HPV was the commonest occurring in $11 \%$ of all smears. Other infections included Trichomonas vaginalis, Gardenella vaginalis, chlamydia and leptothrix.

VIA positivity was seen in $14.5 \%$ ( 58/400) subjects and $85.5 \%$ ( $342 / 400$ ) were VIA negative. 162 patients were tested for High risk HPV of which 58 were VIA positive and 104 were VIA negative. The detection of HPV 16 or 18 DNA by PCR was considered positive and its absence was considered negative. 60 of these 162 cases $(37 \%)$ were positive for HPV 16 DNA and 2 cases (1\%) were positive for HPV 18 DNA. 100 cases (62\%) were negative for either HPV 16 or 18 . Thus a total of $38 \%$ tested cases were positive for high risk HPV of which $96 \%$ were HPV 16 Positive.

Table 2: Comparative table between PAP test, VIA colposcopy and the combination test (VIA + HPV) with reference to biopsy.

\begin{tabular}{|c|c|c|c|c|c|}
\hline Result & Pap test & VIA & HPV 16 & $\begin{array}{l}\text { Colposcopy } \\
\text { (3-8) }\end{array}$ & $\begin{array}{l}\text { VIA } \\
\text { HPV }\end{array}$ \\
\hline Sensitivity & $\begin{array}{c}52.7 \% \\
(19 / 36)\end{array}$ & $\begin{array}{c}91 \% \\
33 / 36\end{array}$ & $\begin{array}{l}86.1 \% \\
31 / 36\end{array}$ & $\begin{array}{c}74 \% \\
27 / 36\end{array}$ & $\begin{array}{l}80.6 \% \\
29 / 36\end{array}$ \\
\hline Specificity & $\begin{array}{c}95.12 \\
(39 / 41)\end{array}$ & $\begin{array}{c}39 \% \\
16 / 41\end{array}$ & $\begin{array}{l}56.1 \% \\
23 / 41\end{array}$ & $\begin{array}{c}68 \% \\
28 / 41\end{array}$ & $\begin{array}{l}68.3 \% \\
28 / 41\end{array}$ \\
\hline Positive Predictive Value & $90.4 \%$ & $57 \%$ & $63.3 \%$ & $66 \%$ & $89 \%$ \\
\hline Negative Predictive Value & $69.4 \%$ & $84 \%$ & $82.1 \%$ & $73 \%$ & $80 \%$ \\
\hline Percentage of False Negatives & $47.3 \% \%$ & $9 \%$ & $14 \%$ & $26 \%$ & $19.4 \%$ \\
\hline Percentage of False Positives & $4.78 \%$ & $61 \%$ & $63.9 \%$ & $32 \%$ & $31.7 \%$ \\
\hline
\end{tabular}

Biopsy positive mild dysplasia or worse (moderate dysplasia, severe dysplasia, carcinoma in situ). 
Colposcopy was done in all 400 patients and scored according to Reid's colposcopic index. A score of 3-8 was considered positive with regard to dysplasia.

Amongst the 77 abnormal colposcopies 37 (48\%) had a Reid score of 0 to 2 and were considered negative. $40(52 \%)$ had a positive colposcopy (Reid 3-8).

Cervical biopsy was done on all 77 patients found abnormal on any of the three screening methods. 36 out of $77(46 \%)$ biopsies were positive and 41 out of 77 (54\%) biopsies were negative. The 36 positive biopsies included 18 mild dysplasia, 5 mild dysplasia with condylomatous change, 5 moderate dysplasia, 5 severe dysplasia and 3 carcinoma in situ.

The individual tests - VIA, Pap smear, Colposcopy and HPV were analysed with reference to biopsy. Table 2 shows a comparative table of the performance of the various tests.

The sensitivity of test (VIA + HPV) for low grade dysplasia was $80.6 \%$ which was lower than that of VIA alone $(91 \%)$ and lower than that of HPV DNA detection alone $(86 \%)$. The specificity of the test (VIA + HPV) was $68.3 \%$ which was significantly higher than that of VIA alone $(39 \%)$ and also higher than that for HPV DNA detection when used alone $(56 \%)$. Thus, secondary triage testing by high risk HPV DNA testing in VIA positive cases improves the specificity of VIA as a screening test for cervical dysplasia with a small reduction in its sensitivity. The improvement in the specificity of VIA by the addition of HPV DNA testing was found to be statistically significant $(\mathrm{p}=0.000)$.

If Instead of HPV testing Pap smear is used to triage women who are VIA positive, the sensitivity of the test would be only $44 \%(16 / 36)$ but the specificity would be $100 \%(41 / 41)$.

\section{DISCUSSION}

In this study we have evaluated the performance of VIA, Pap smear, High risk HPV DNA testing and colposcopy as screening modalities for cervical cancer. We have also presented an assessment of the performance of a combination test of VIA and HPV DNA testing as a screening modality. This combination has also been compared with a combination of VIA with pap smear.

Pap smear has been the standard screening test for cancer cervix detection in India. However it has been shown to have a low sensitivity varying from 51 to $84 \%^{8,9,10,11}$ resulting in a high false negative rate varying from $25-48$ $\%$.The sensitivity of Pap smear has been found to be even lower in developing countries, specially with regards to lower grade of abnormality. The possible reason for this may be the large percentage of cervicitis and inflammatory smears which mask mild dysplasia. ${ }^{12}$ In our study the sensitivity was found to be $52.7 \%$ which was comparable to that found in the meta-analysis of 85 studies by AHCPR where it was $51 \%{ }^{11}$

The specificity of cytology is however high. Our study showed $95.12 \%$ specificity which compares well with other studies which have shown the specificity to range from 95 to $99.8 \%$ with a low false positive rate of only 0.2 to $1 \% .^{8-10,13}$

There are many limitations of Pap smear besides its low sensitivity. Large scale screening requires infrastructure and technical staff which may not be available in developing countries. Also follow up visits are required for which our patients may not be compliant. These factors had forced the health providers to look at alternative screening modalities for screening for cancer cervix.

VIA is being investigated as an alternative screening modality. Various studies have shown the sensitivity of VIA is high and ranges from $63.5 \%$ to $90.1 \%$. $^{14-17}$ However the specificity of VIA has been found to range from $43 \%$ to $92 \%{ }^{14-17}$ This low specificity results in a high number of false positives. In our study VIA had a sensitivity of $91 \%$ and a specificity of $39 \%$.

In order to improve the low specificity of VIA various studies has evaluated the role of a secondary triage procedure. One of these is detection of high risk HPV DNA detection. In our study the combination of HPV detection to VIA showed a sensitivity of $80.6 \%$ and a specificity of $68.3 \%$. In various studies the combination test of VIA + HPV has a higher specificity, ranging from $68-96 \%$ than that of VIA alone. In our study, when HPV testing was added to VIA positive cases, the specificity rose from $39 \%$ to $68.3 \%$. This was statistically significant. Thus if those cases positive by both tests were referred for colposcopy / biopsy, rather than those positive only by VIA, the number of false positive cases would be substantially reduced. The main disadvantage of the combined test is that its sensitivity is less than that of VIA and it will still miss about $20 \%$ of dysplasia.

If we triage the women who are VIA positive with Pap smear the sensitivity would be only $44 \%$ which is unacceptably low for a screening method.

An ideal screening method should not only be feasible on a large scale, but also be cost effective. One of the main advantages of VIA is its low cost. The other advantages are that it is easy to do and can be done in peripheral areas by paramedics on a large scale. HPV DNA testing is a relatively expensive test. Even if mass screening is done the cost would only be marginally reduced. Thus universal screening by HPV is too expensive and not cost effective. However if HPV testing was done only in the VIA positive patients we would require to perform the test only in a small fraction (15\%) of the whole population. When the cost of such a two stage screening is applied we find that it is less than the cost for screening all women with a pap smear. 
If VIA + Pap smear is used as a screening procedure , the total cost will be less as compared to the combination test of VIA + HPV DNA testing but the sensitivity of the VIA + pap smear would be significantly lower than that of the VIA + HPV combination.

The results of this study suggest that a combination of VIA with High Risk HPV DNA testing could be a more effective and more economical tan universal screening by pap smear, especially in low resource settings.

Funding: No funding sources

Competing interests: None declared

Ethical approval: The study was approved by the Institutional ethics committee

\section{REFERENCES}

1. Parkin DM, Bray F, Ferlay J, et al. Estimating the world cancer burden: Globocan 2000. Int J Cancer 2001;94:153-6.

2. Luthra UK, Kotwani BG, Kochhar M, Khurana B, Seth P, Mahopatra LN, Mitra AB, Bhatnagar P, Prabhakar AK, Aggarwal SS, Pant JN, Khan IU. Indian J Med Res 1983;8:60-6.

3. Bosch FX, Munoz N. The viral etiology of cervical cancer. Virus Research 2002;89:183-90.

4. Sujathan K, Kamman S, Pillai KR, Mathew A, Joseph M, Syamalakumari B, Nair MK. Implications of gynecological abnormality in preselection criterion for cervical screening: preliminary evaluation of 3602 subjects in South India. Cytopathol 1995;6:75-87.

5. Kouri MT, Morsberger S, Carrillo A, Mohar A, et al. HPV prevalence among Mexican women with neoplastic and normal cervices. Gynaecol Oncol 1998;70:115-20.

6. Kailash U, Hedau S, Gopalakrishna V, Katiyar S, Das BC. A simple paper method for dry collection, transport storage of cervical cytological specimens for rapid screening of HPV infection by PCR. J Med Microbiol 2002;51:606-10.

7. Reid R, Scalzi P. Genital warts and cancer. An improved colposcopic index for differentiating benign Papilloma viral infection from high-grade cervical intraepithelial neoplasia. Am J Obstet Gynecol 1985;153:611-8.

8. Soost HJ, Lange HJ, Lehmacher W, Ruffinger Kullman B: The validation of cervical cytologysensitivity specificity and predictive value. Acta Cytol 1991;35:8-14.

9. Di Bonito L, Falconieri G, Tomasic G, Colautti I, Bonifacio D, Dudine S: Cervical cytopathology - An evaluation of its accuracy based on cytolohistologic comparision. Cancer 1993;72:3002-6.

10. Vander Graff, Voojis GP: False negative rates in cervical cytology. J Clin Pathol 1987;40;438-42.

11. Mc Crory DC, Matchar BB, Bastain L, et al Evaluation of cervical cytology. Evidence report Technology assessment No. 5 AHCPR publication No. 99-E010, Rockville, MD: Agency for Health care Policy and Research. 1999.

12. Memoranda-Cervical cancer control in developing countries: Memorandum from a WHO meeting, WHO Bulletin OMS. 1996; Vol.74.

13. Cronje HS, Parham GP, Cooreman BF, de Beer A, Divall P, Bam Rh. A comparison of four screening methods for cervical neoplasia in a developing country. Am J Obstet Gynecol 2003;188:395-400.

14. Memoranda-Cervical cancer control in developing countries: Memorandum from a WHO meeting, WHO Bulletin OMS. 1996; vol.74.

15. Sankarnarayan R, Wesley R, Somanathan T, Dhakad N, Shyamalakumary B, Amma NS, et al. Visual inspection of the uterine cervix after the application of acetic acid in the detection of cervical cancer and its precursors. Cancer 1998;83:2150-6.

16. University of Zimbabwe/ JHPIEGO Cervical Cancer Project. Visual inspection with acetic acid for cervical cancer screening: Test qualities in a primary - care setting. Lancet 1999;353:869-73.

17. Belinson J, Pretorius R, Zhange W, Wu LY, Qiao Y, Elson P. Cervical cancer screening by simple visual inspection after acetic acid. Obstet Gynecol 2001;98:441-4.

DOI: $10.5455 / 2320-1770 . i j r \operatorname{cog} 20130608$

Cite this article as: Gami N, Gandhi G, Batra S, Zutshi V, Das BC, Bhambhani S. Role of visual inspection of cervix with acetic acid and high risk human papilloma virus DNA testing in screening for cervical cancer. Int J Reprod Contracept Obstet Gynecol 2013;2:152-6. 